\title{
Investigating user satisfaction of university online learning courses during the COVID-19 epidemic period
}

\author{
Yiting Zuo \\ University of International \\ Business and Economics \\ 17862326272@163.com
}

\author{
Xusen Cheng \\ Renmin University of \\ China \\ xusen.cheng@ruc.edu.cn
}

\author{
Ying Bao \\ University of International \\ Business and Economics \\ 2426252877@qq.com
}

\author{
Alex Zarifis \\ University of \\ Loughborough \\ alex.e.zarifis@gmail.com
}

\begin{abstract}
Online learning has been expanding for some time but the forced move to it due to the outbreak of COVID-19 has created new issues. This study set out to investigate the impact mechanism of online learning user satisfaction from the perspective of cognitive load in the era of COVID-19 and explore ways to optimize cognitive load in teaching practice. Semi-structured interviews were conducted for the empirical analysis. The coding process of the interviews yielded several antecedents of cognitive load in the online learning process. We also proposed a theoretical model based on the literature review and data analysis. Findings of the qualitative analysis indicate that the antecedents of cognitive load are multi-dimensional and the user's satisfaction with the online learning platform mainly consists of the expected confirmation of the information system and the perceived usefulness. These findings can help us think backward about optimizing user satisfaction with online learning in the context of COVID-19 breakout.
\end{abstract}

\section{Introduction}

Online learning is an extremely important part of education. Online learning gets continually increasing popularity worldwide, reducing the time and space conflicts compared to the traditional form of education approaches [1]. By learning from the experience of COVID-19, we can guarantee the continuity of education with engaging and rewarding online learning and avoid being disrupted by new natural disasters.Class formation in online learning is a critical task that impacts quality and retention [2].

An individual's ability to use his working memory to process information and make decisions is affected by the cognitive load they perceive. Cognitive load refers to the total amount of mental effort being used in the working memory [3]. In the context of this research, the cognitive load in online learning is not only determined by the internal load of the material that needs to be learned, but also involves the influence of many external load factors such as the design of the teaching process and the complexity of the information system used.

For example, the knowledge reversal effect rising from the repetition effect, and the repetitive effect comes directly from the distraction effect, and the attention distraction effect comes directly from the sample effect, which is explained from the internal effect of cognitive load [4]. Secondly, teachers using online learning platforms or presenters who set up improper teaching procedures will also generate external cognitive load. As cognitive load is the total mental effort of learning and memory used in the online learning process [5], this is the cost of a cognitive task that affects user satisfaction [6]. Different individual cognitive levels will also produce different cognitive loads. Therefore, the study of user satisfaction in online learning, from the perspective of cognitive load, is very helpful to the platform to optimize the user experience and promote the development of online learning.

Adopting the Cognitive Load Theory (CLT), this study mainly focuses on the antecedents of cognitive load generated by external factors. It explores the internal influence mechanism of cognitive load on user satisfaction combined with the theory of expectation confirmation. At the same time, we also explore whether the level of cognitive ability will affect user satisfaction. According to the above research background and research gaps, this study attempts to answer the following research questions: (1) In the context of the COVID-19, what are the factors that affect cognitive load? (2) How does cognitive load affect the satisfaction of online learning users, and what is its internal influence mechanism? (3) Will an individual with a different cognitive ability perceive different levels of cognitive load for the same online learning task?

\section{Theoretical background}

After initially closing because of COVID-19, universities are resuming teaching gradually. Online learning will eventually shift from a novelty to "the 
new normal". In the past, online learning played a complementary role to traditional education. During the period of COVID-19, online learning has completely replaced offline learning, and has been implemented on such a large scale for the first time across the whole world.

\subsection{Online learning}

Since China launched the pilot network education for higher education, although there are still some problems in terms of enrollment standards, teaching quality and security supervision, it has accumulated more than 20 years of experience [7]. Since the end of the 1990s, a distance education platform using the Internet as a medium has emerged, and online learning education in China entered the first stage. After that, since 2013, due to the involvement of Internet companies, large-scale online courses have emerged, and online learning has entered the second rapid development stage.

With the growth of individuals' learning needs, the use of computer networks and other information technologies in education has been widespread and ubiquitous, especially in the developed countries. Online learning has risen rapidly and continues to develop rapidly. Online learning is becoming a new favorite in the field of education in the United States where information technology is highly developed [8].

Online learning has received extensive attention, not only in the social isolation context nowadays but also in the future teaching and learning practice. There are still many issues associated with the effectiveness of online learning need improvement. Domestic research on online learning focus on the study of influencing factors. Specifically, the various teaching phenomena that appear in the example of Massive Open Online Courses (MOOC) are discussed frequently by scholars. Foreign scholars are mainly concerned about the effect of online learning on the promotion of a professional group, while the investigation into the mediation effects or influence mechanism is still limited.

\subsection{Cognitive load}

Cognitive Load Theory (CLT) was proposed by Australian psychologist John Sweller in 1988 [9].

Domestic researchers have commented on the progress and development of the applied research on human payment theory abroad. Combined with the SSCI/SCI database, it was found that the Australian scholar Sweller's paper on CLT published in 1988 has been widely cited, and the cited literature is distributed in the fields of education, psychology, computer science, business economy, library and information, etc. CLT has become the important theoretical basis of the relevant discipline [10]. In the context of online learning, $\mathrm{Li}$ et al. [11] analyzed the mapping relationship between knowledge types and design elements based on multi-dimensional attributes, and the paths to optimize cognitive load using knowledge visualization. Jean et al. [12] analyzed the effect of multimedia presentation and pointed out that when low-level learners use multimedia to read auxiliary content and they constantly switch information sources, this results in more "distraction" and increased cognitive load. High levels of cognitive load will prevent them from learning and understanding the materials. The development of education is also including a process of obtaining information. Epler et al. [13] held the view that information overload will occur when the amount of information provided exceeds the information processing ability of the individual's cognitive ability.

According to existing research on cognitive load and effective teaching, these studies mainly focus on the design of teaching content, the difference between teaching content and the knowledge level of learners. The traditional university curriculum has three basic elements, represented by teachers, students, and teaching materials, which are represented in three dimensions [14]. Recently, the development capabilities of the Internet has penetrated into all walks of life. The endless appearance of variety online learning platforms has broken the restrictions between teaching and learning on the time and geographical problem, decoupled the teacher and student timeline, and the constraints of space expansion activities. It represents the development direction of adapting to independent learning and has aroused great attention from all walks of life.

Regarding the long continuous time of university courses, weak knowledge structure and complicated knowledge points, students are generally in a state of high cognitive load.

Through research on the influence of prior knowledge on teaching effectiveness, Lee et al. [15] found that attempting to reduce external cognitive load is likely to lead students with high-level prior knowledge to construct a redundant cognition framework. This contradiction was particularly prominent during COVID-19. In the context of this research, CLT provides a theoretical framework for the cognitive process, cognitive limitations, and online platform curriculum design. Therefore, it is urgent to investigate the source and find effective learning concepts and methods to help college students reduce load or use cognitive load reasonably to learn and 
master knowledge more efficiently. It is an urgent problem to be solved by educators.

\subsection{Expectation confirmation}

The Expectation Confirmation Model (ECM) proposed by the famous American scholar Anol Batacheree is developed based on the Expectation Confirmation Theory (ECT) proposed by Oliver [16]. Some scholars also call it the Information System Expectation Confirmation Model (IS-ECM) for the using to investigate the classic common theoretical model of the continuous use of questions after the adoption of information systems,

ECT was initially adopted to ascertain the relationship among factors that affect consumer repurchase behavior. Lin et al. [17] extracted the concept of "net worth" from a value-based model, which means the comparison of benefits, costs and satisfaction. It argues that it is not enough to study only the positive attitudes of consumers, especially if the products or services are not obtained without cost. Bhattacherjee et al. [18] applied a slightly modified ECT in the field of information systems and the original ECT ignored potential changes by consumers.

The revised ECT was modified based on others' opinions or the expectations of the information disseminated through the mass media, so that the expectations after acceptance that are influenced by the consumer's first-hand experience can reflect the true will more. Wolverton et al. determine a minimal set of expectations through ETC, because existing researches mostly used one-dimensional expectations [19]. International surveys of the Chief Information Officer (CIO) and other senior IT outsourcing practitioners have proven that these expectations can be combined to affect outsourcing from original submission.

According to the definition of cognitive load on the effort of retrieving information, many scholars have adopted CLT to study personal information retrieval related issues, while others study the distribution of cognitive load from collaborative information retrieval behavior. This includes the impact on the design of information systems, human-computer interaction interfaces [20] and the design of interface elements from a microscopic perspective [21]. At the same time, the online learning platform serves as an information system, and evaluating whether it can help users complete tasks is an important factor in evaluating the success of an information system. Therefore, some scholars usually evaluate the effectiveness of various functional designs of information systems from the perspective of cognitive load and usually from the functional design of information systems. McKinney et al. [22] studied the expectations of users of the recommendation system to reuse, and believed that various stimuli in the online shopping environment will affect consumers' emotional and cognitive processes, which in turn affect consumers' cognition processing.

In summary, it is not difficult to conclude that perceived usefulness and confirmation expectations are the antecedents of user satisfaction and expectation confirmation can affect perceived usefulness.

As a widely used form of education, online learning inevitably involves writing content in daily teaching activities, such as virtual writing or semivirtual collaboration based on information systems.

The effect of collaboration directly affects learning performance, and the previous evaluation of individual cognitive load levels is still limited in the adoption of information systems. Compared with the online collaboration of multi-person teams, the former evaluation method is obviously inappropriate.

\subsection{Cognitive ability}

Cognitive ability can comprehensively measure individual ability. Our experience is encoded based on established knowledge system, and the integration of new information will be affected by the knowledge already learned. Bein et al. [23] conducted experiments and manipulated the participants to view the repeated behaviours and record the observations. The results show that prior knowledge facilitates processing and reduces reaction time.

Online learning users construct concepts from a priori knowledge. Therefore, the study of individual differences in learners' cognitive abilities in this research scenario can be reflected as differences in prior knowledge. Lee et al. [15] studied the influence of a priori knowledge on the effect of teaching. Positive organizational behavior studies suggest that when faced with stress, different individuals respond differently. Individual characteristics and resources are important influencing factors for individuals to cope with stress [24]. Therefore, effective online learning activities must take specific measures to optimize their cognitive load and improve learning performance according to different levels of prior knowledge of learners.

Psychological resilience refers to the ability of an individual to effectively adjust from adversity, conflict, failure, and even rapid changes, process and responsibility expansion [25]. This global-scale online learning has accompanied the progress of the epidemic almost all the time. It is a very important link to explore the sources of online learning users' cognitive load. Wu et al. [26] conducted a questionnaire survey on 194 young people and studies have shown that the psychological resilience index is closely related to 
mental health and well-being. Kermott et al. [27] found that high elasticity is positively correlated with happiness and negatively correlated with perceived stress.

In the context of COVID-19, psychological resilience can help users overcome the panic and pressure of infectious diseases. It can also guide users to make favorable choices and coping strategies when facing epidemics, pressures and challenges [28]. Domestic scholars combined the work demandresource model and resource protection theory to construct and test the intermediary model between challenging and obstructive stressors and emotional fatigue and concluded that psychological adaptability can play a regulatory role [29]. It shows that people with different psychological adaptability will produce different degrees of stress when dealing with adverse external stimulus.

\section{Methods and research design}

This study conducted semi-structured interviews using interview outlines that are based on the research questions. At the same time, we also include open questions. We interview college students who have experience with using online learning before. The interviews were recorded and transcribed into the interview draft. Antecedents of cognitive load will be summarized according to the interview data, and the influence mechanism related to user satisfaction.

\subsection{Case study and data collection}

We selected undergraduate and postgraduate students who have studied online at several different universities in the country in the first half of 2020 for the perpus to discover the true feelings and satisfaction of online learning users with online learning platforms during the epidemic. The interviewee conducted indepth interviews with different users in two stages.

At the beginning of the online course, about 20 undergraduate students were randomly selected for the first interview. In the second stage, major mainstream online learning platforms have been continuously optimized and improved, and the blending of teachers and students has been stabilized. A second and more in-depth interview was conducted with 10 undergraduate students who have completed all their online courses. In addition, more information about online courses, news and public comments have been released, and people have paid more attention to online learning platforms. At the same time, the Chinese government issued a policy document on the continued development of online learning. It turns out that all these factors will affect users' trust in online learning platforms. Therefore, we asked some appropriate questions summed up from previous research and interviewed users who use the online learning platform. Throughout the process, we transcribed each interview and fully analyzed the content.

\subsection{Data analysis and coding}

In this process, we collected empirical data to enrich and support our research on the antecedents of satisfaction. We encode the transcript through Nvivo11 to extract key fields to identify the antecedents and impact mechanisms of satisfaction. For data visualization, we used processed interview records to generate a word cloud (Figure 1) to show the highfrequency concepts involved in this research.

As for the coding process, the first step is to extract the important individual case and the original statement about online learning. Then we conceptualize the initial definition based on mature theory and integrate the same concept into one consruction. In order to be more organized, we use the Table 1 to show the final results.

After the initial coding process, we summarized the factors that affect the cognitive load of users related to the online learning platform, and rigorously described each antecdent of cognitive load.

\section{Research model and hypotheses}

According to the literature reviews and interviews, we propose the model shown in Figure 2. The study focuses on the new scenario of "new crown epidemic" through qualitative analysis of interview data. The purpose is to derive the load source factors that affect platform user satisfaction in the context of online learning, and to work backwards to understand which will worsen the cognitive load.

Furthermore, we conducted this modle to summarizes the factors that promote the improvement of cognitive load and improve user satisfaction from the specil perspective, widens the application boundary of CLT, and makes theoretical contributions to the existing literature on cognitive load.

Cognitive load and performance are two prerequisites that affect satisfaction. The definition of perceived usefullness of the ECM model (Figure 3) is similar to performance. They all represent the final grades of students in teaching. Past research is generally based on case studies, from the positive verification of factors that affect satisfaction. Therefore, this model combines the above two models, and sorts out the different influencing factors in the new situation and before based on the interview analysis, to explore the impact mechanism of cognitive load on 
user satisfaction. The current CLT research lacks comment on the latest applied research and there is no research review in information systems and other fields [30]. This paper expands the model of satisfaction theory by combining the new model proposed by the information system media under the "new crown epidemic situation".

Table 1. Results of the opening coding (portion)

\begin{tabular}{|c|c|c|c|}
\hline \multirow{2}{*}{ Original statement (interviews on users) } & \multicolumn{3}{|c|}{ Coding Process } \\
\hline & Definition & Conceptualization & Categorization \\
\hline $\begin{array}{l}\text { I don't want to turn on the camera, but also worry } \\
\text { about leaking my private life(a1).....I am very } \\
\text { worried about the infection of myself and the } \\
\text { people around me(a2)...... During the epidemic, } \\
\text { restricting going out would affect many aspects of } \\
\text { my study, such as being afraid to go to the hospital } \\
\text { when I was sick, unable to go out to print learning } \\
\text { materials, and purchasing school supplies(a3). }\end{array}$ & $\begin{array}{l}\text { a1 Privacy violation } \\
\text { a2 Infectious } \\
\text { diseases } \\
\text { a3 home isolation }\end{array}$ & $\begin{array}{l}\text { A1 Anxiety(a1, a2, } \\
\text { a3) }\end{array}$ & $\begin{array}{l}\text { AA1 } \quad \text { Perceived } \\
\operatorname{risk}(\mathrm{A} 1)\end{array}$ \\
\hline $\begin{array}{l}\text { When I was taking online classes, I expressed } \\
\text { myself more calmly and actively(a4)......I felt } \\
\text { strenuous when communicating with the team } \\
\text { members(a5)...... When the classroom atmosphere } \\
\text { is active, I will focus more on learning(a6). }\end{array}$ & $\begin{array}{l}\text { a4 Class interaction } \\
\text { a5 Teamwork } \\
\text { a6 Classroom } \\
\text { atmosphere }\end{array}$ & $\begin{array}{l}\text { A2 Influence of } \\
\text { related people } \\
\text { around(a4, a5, } \\
\text { a6) }\end{array}$ & $\begin{array}{l}\text { AA2 Social } \\
\text { factors(A2) }\end{array}$ \\
\hline $\begin{array}{l}\text { I have more time to prepare for my } \\
\text { studies(a7).....I can choose a quieter and more } \\
\text { comfortable environment to take classes(a8).....I } \\
\text { can check for missing vacancies at any time (a9). }\end{array}$ & $\begin{array}{l}\text { a7 Sufficient } \\
\text { preparation time } \\
\text { a8 Choose a place } \\
\text { that is good for } \\
\text { learning } \\
\text { a9 Learn according } \\
\text { to the situation }\end{array}$ & $\begin{array}{l}\text { A3 Reasonable } \\
\text { arrangement of time } \\
\text { (a7, a8) } \\
\text { A4 Reasonable } \\
\text { arrangement of places } \\
\text { A5 Control the } \\
\text { learning process(a9) }\end{array}$ & $\begin{array}{l}\text { AA3 Perceived } \\
\text { autonomy(A3 , } \\
\text { A4, A5) }\end{array}$ \\
\hline $\begin{array}{l}\text { Teachers will distribute multimedia materials in } \\
\text { advance(a10).....Teachers usually review and } \\
\text { answer the questions in the previous lesson before } \\
\text { explaining the knowledge of this lesson(a11)..... } \\
\text { will arrange my courses more evenly so that I have } \\
\text { enough time to prepare for other things(a12). }\end{array}$ & $\begin{array}{l}\text { a10 Rich course } \\
\text { content } \\
\text { a11 Reasonable } \\
\text { course content } \\
\text { organization } \\
\text { a12 Reasonable } \\
\text { course organization }\end{array}$ & $\begin{array}{l}\text { A6 Online course } \\
\text { content quality(a10, } \\
\text { a11, a12) }\end{array}$ & $\begin{array}{l}\text { AA4 Content } \\
\text { quality(A6) }\end{array}$ \\
\hline $\begin{array}{l}\text { Sometimes I accidentally "raise my hand" or quit } \\
\text { class(a13).....I like e easy-to-use } \\
\text { software(a14)......I sometimes experience software } \\
\text { crashes(a15). }\end{array}$ & $\begin{array}{l}\text { a13 Operation error } \\
\text { a14 Simple function } \\
\text { a15 Stable } \\
\text { performance }\end{array}$ & $\begin{array}{l}\text { A7 User } \\
\text { experience(a13, } \\
\text { a14,a15) }\end{array}$ & $\begin{array}{l}\text { AA5 Self- } \\
\text { efficacy(A7) }\end{array}$ \\
\hline $\begin{array}{l}\text { I think online courses will be easier than offline } \\
\text { courses(a16)...... f feel that online exams are } \\
\text { complicated and I can't concentrate (a17)......I fell } \\
\text { sometimes the course progresses fast, and the group } \\
\text { display time is usually not enough(a18). }\end{array}$ & $\begin{array}{l}\text { a16 Easy work } \\
\text { a17 Examination is } \\
\text { difficult } \\
\text { a18 Curriculum is } \\
\text { unreasonable }\end{array}$ & $\begin{array}{l}\text { A8 Internal } \\
\text { cognitive load(a16, } \\
\text { a17) } \\
\text { A9 External } \\
\text { cognitive load } \\
\text { (a18) }\end{array}$ & $\begin{array}{ll}\text { AA6 } & \text { Cognitive } \\
\text { load(A8, } & \text { A9) }\end{array}$ \\
\hline $\begin{array}{l}\text { I think the software used in the class is very } \\
\text { complete and can meet my requirements(a19). }\end{array}$ & $\begin{array}{l}\text { a19 Meets users' } \\
\text { expectations }\end{array}$ & $\begin{array}{l}\text { A10 Expectation } \\
\text { confirmation(a19) }\end{array}$ & $\begin{array}{l}\text { AA7 Expectation } \\
\text { confirmation(A10) }\end{array}$ \\
\hline $\begin{array}{l}\text { I am not very satisfied with my grades this } \\
\text { semester(a20).....I am not efficient enough to } \\
\text { study(a21). }\end{array}$ & $\begin{array}{l}\text { a20 Final grade } \\
\text { a21 Learning } \\
\text { efficiency }\end{array}$ & $\begin{array}{l}\text { A11 Learning } \\
\text { performance } \\
(\mathrm{a} 20, \mathrm{a} 21)\end{array}$ & $\begin{array}{l}\text { AA8 Perceived } \\
\text { usefulness(A11) }\end{array}$ \\
\hline
\end{tabular}




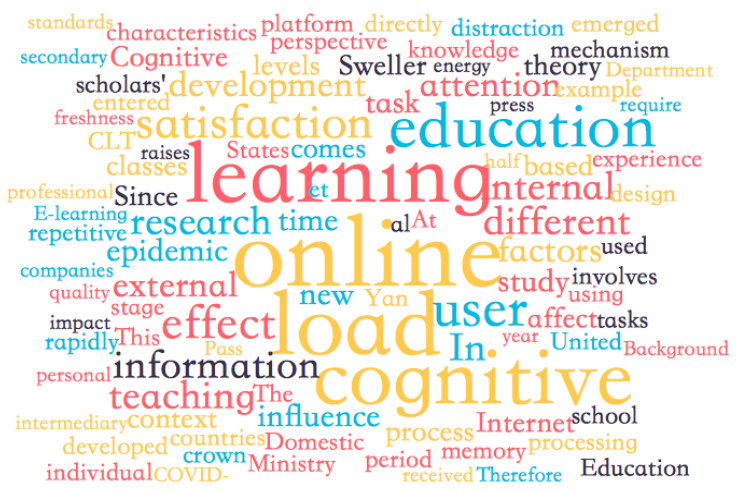

Figure 1. Indicative word cloud of transcripts

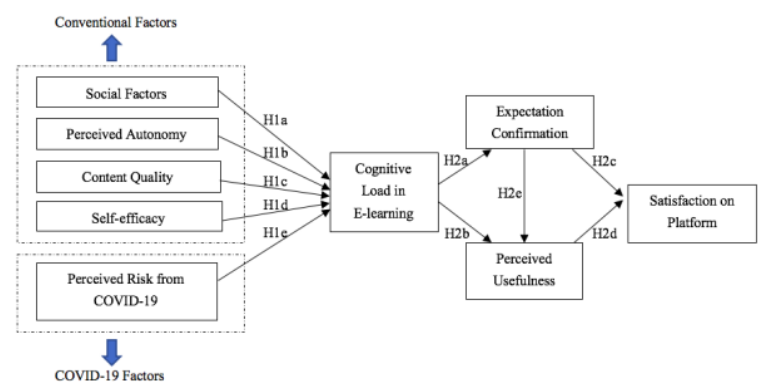

Figure 2. Research model of satisfaction for online learning user

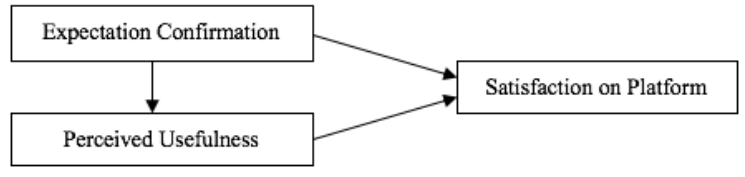

Figure 3. The Expectation Confirmation Model

Social factors are similar to the subjective norms in the planned behavior theory (TPB) and social factors in the social cognitive theory (SCT).

From the perspective of social cultural constructivism, the interaction between students and teachers is conducive to promoting knowledge construction [31].

At the same time, most of the students in the interview mentioned that in the live online learning, because online participants cannot "see" other participants, they are more inclined to express their opinions and communicate with students and teachers more easily [32]. During the presentation session, the synchronous communication tool not only allows multiple users to communicate using SMS, but also enhances the student's learning outcomes, thereby reducing cognitive load. In the context of this study, social factors refer to users being influenced by the suggestions and behaviors of important people around them during the online learning process.

In summary, we propose the following hypotheses about traditional factors:

H1a. Social factors has a significant negative effect on cognitive load.

Perceived autonomy means increased flexibility in terms of time, place of participation and learning progress, and this also reveals that the more autonomy students have in online learning, the more problem of inability to concentrate at the same time they will faced [33][34]. More specifically, autonomy comes from realization involving personal responsibility, self-control, devotion, cognitive dedication, etc. [35]. Matthias et al. draws on models of self-regulated learning theory and CLT to develop further to advance perceived autonomy and CLT [36]. In the online learning process, the higher the user's autonomy is, the worse beneficial it is to optimize cognitive load.

In summary, we propose the following hypotheses about traditional factors:

H1b. Perceived autonomy has a significant negative effect on cognitive load.

Content quality refers to the quality of the online learning platform course content in the context of this research. A widely used practice is that cognitive load can be optimized through planning and flexible content management and cooperative learning [37].

In view of the limited working memory ability of learners, devoting to improving the quality of learning content can reduce redundancy and complexity, weaken the internal cognitive load and enhance the professionalism of learners [38][39].

In summary, we propose the following hypotheses about traditional factors:

H1c. Content quality has a significant negative effect on cognitive load.

Self-efficacy refers to the ability of users to perceive whether they are qualified for this task when experiencing new learning methods. Similarly, it is also an observation point for the assessment of ability, which can be traditionally understood as selfconfidence. Murat et al. proposed that self-efficacy and preventive behaviors derived from the severity of COVID-19 are related to mental health or cognitive ability [40]. An AR-Based Case Study conducted by Liu et al. [41] showed that well-designed collaboration can guide students with low self- 
efficacy in deep learning and effectively reduce the cognitive load. The stronger the user's self-efficacy, the stronger the self-confidence of the online learning task. Thus, we propose the following hypotheses about traditional factors:

H1d. Self-efficacy has a significant negative effect on cognitive load.

If the user is subjectively more concerned about the changes in their own physical health and the degree of impact on the social environment, there will be expected perceived risk, then the risk is conceptualized as subjective uncertainty [42][43]. Users are likely to face potential psychological obstacles when learning online. For example, Lee et al. [44] develop an extended model that processes the perceived risk of influenza virus as a bad influence factor on online learning. High-risk concept is also an obstacle to travel intention [45] and force users to spend more time searching for relevant information to avoid risks [46]. In online learning, sharing information through the platform including using voice and the camera will also cause more privacy issues, compared with the period before the epidemic [47][48].

In summary, perceived risk can be used as a special influencing factor of COVID-19 to measure the user's perception of cognitive load in this regard.

Therefore, we propose the following hypothesis:

H1e. Perceived risk has a significant negative effect on cognitive load.

Some schoolers recently investigated the relationship between expectation and cognitive load, and the findings show that when users pay lower cognitive effort, the sensory information and expectation confirmation match [49][50]. Therefor, we propose the following hypotheses:

H2a. Cognitive load has a significant negative effect on user expectation confirmation.

Many studies have verified that cognitive load could be a very critical keys explaining seasons for achievement, especially based on online learning [51][52].When it comes to High cognitive load conditions, significantly decreasing of the systems score of perceived usefulness and the user's ability to recall the responses get obviously [53]. In summary, we propose the following hypotheses:

H2b. Cognitive load has a significant negative effect on perceived usefulness.
Satisfaction with the information system depends on the degree to which the website meets these expectations proposed by ETC [18]. If people achieve the desired performance results with reduced cognitive ability, they will be more satisfied with the platform [54]. Relevant research on post-adoption needs to be taken seriously, as existing discussions are more focused on the pre-factors of initial adoption of information technology (such as mobile wallets). [55][56].

Therefore, we propose the following hypothesis:

H2c. Expectation confirmation has a significant positive impact on satisfaction.

Perceived usefulness refers to the efficiency users perceived that the platform produced. Perceived usefulness is not only related to the user's initial adoption of the information system [57], which has strong relation to ECT, but also an important factor that affects user satisfaction and continued use intentions [58].

Subsequent research also concur that there is a positive correlation between perceived usefulness and user satisfaction [59][60]. It showed that perceived usefulness has a direct impact on user satisfaction.

Therefore, we propose the following hypothesis:

H2d. Perceived usefulness has a significant positive effect on satisfaction.

Expectation and performance are two important concepts in expectation confirmation theory. The concept of fair performance comes from the theory of equity expresseing that performance norms based on personal costs and investment and expected returns [61]. What's more, Anil et al. [62] developed a model verified that pre-adoption performance/effort expectations affects user confirmation, and then affects post-adoption perceived usefulness, perceived safety, and user satisfaction. Therefore, we regard perceived usefulness as post-adoption and the expect confirmation to be understood as pre-adoption to propose the following hypotheses:

H2e. Expected confirmation has a significant positive effect on perceived usefulness.

\section{Conclusion and future research}

\subsection{Conclusion}

Online learning is vital to educational reform. This research puts forward new insights on the 
impact mechanism of user satisfaction on online learning platforms, involving the context of the COVID-19 breakout. It meticulously distinguishes cognitive load antecedents in different aspects. In this study, we summarized some preliminary conclusions based on the questions raised at the beginning of the study.

For the first research question, we found that the influencing factors of cognitive load are very strongly related to the of platform satisfaction. They can be divided into conventional factors and specific factors that are caused by the COVID-19. The conventional factors include social factors, perceived autonomy, content quality, and self-efficacy.

For the second research question, we found that the antecedents of satisfaction which were mentioned by most of the users interviewed repeatedly can be summed up in two constructs. One of the two is expectation confirmation which has more to do with the information system, and the other is perceived usefulness that has a connection with learning performance. The relationship is very complicated among those nodes.

For the last research question, a very typical phenomenon shows that the cognitive load perceived by people with different educational levels may be a research gap. Therefore, a separate study should be conducted to excavate the differences among users with different cognitive ability. This is extremely significant for personalized education.

\subsection{Limitation and future research}

As this research is still in the process of iterative exploration, it still has many unknowns and research flaws. First of all, this research only investigated the satisfaction with online learning platforms of higher education university students. However, as the background of the continuous development of the current online learning platform, the investigation of the majority of primary and secondary school students cannot be ignored. Second, due to time and financial constraints, our data is limited. Third, in the following data collection, more attention should be paid to the development of questionnaires, and user reviews of mainstream online learning platforms in the application store should be collected to test the improved model.

In future research, we may pay more attention to the collaboration of users with different educational levels and the willingness to continue using the online learning platform. In addition, the interview data that has been collected is more focused on breadth of exploratory research. After that, more interviews and in-depth exploration are needed to achieve a combination of qualitative and quantitative methods to correct the model, and in a practical sense contribute to the scientific research of online learning.

\section{Acknowledgement}

The authors would like to thank National Natural Science Foundation of China (Grant No. $72061147005,71571045)$ for providing funding for part of this research. Xusen Cheng is the corresponding author.

\section{References}

[1] R. Panigrahi, P.R. Srivastava, and D. Sharma, "Online learning: Adoption, continuance, and learning outcome-A review of literature", International Journal of Information Management, 43, 2018. pp. 114.

[2] P.D. Meo, F. Messina, D. Rosaci, and G. M. L. Sarné, "Combining trust and skills evaluation to form eLearning classes in online social networks", Information Sciences, 405, 2017, pp. 107-122.

[3] F. Paas, A. Renkl, and J. Sweller, "Cognitive load theory: Instructional implications of the interaction between information structures and cognitive architecture", Instructional Science, 32(1/2), 2004, pp. 1-8.

[4] J. Sweller, "Element Interactivity and Intrinsic, Extraneous, and Germane Cognitive Load", Educational Psychology Review, 22(2), 2010, pp. 123-138.

[5] F. Paas, A. Renkl, and J. Sweller, "Cognitive Load Theory and Instructional Design: Recent Developments", Educational Psychologist, 38(1), 2003, pp. 1-4.

[6] H. Yan, E. Chang, T. Chou, and X. Tang, "The OverCategorization Effect: How the Number of Categorizations Influences Shoppers' Perceptions of Variety and Satisfaction", Journal of Business Research, 68(3), 2015, pp. 631-638.

[7] Y. Fu, Q. Huang, "Status, Problems and Development Strategies of Online Degree Education in Chinese Universities", Jiangsu Higher Education, 2020.

[8] M. Zhang, X. Ding. "Online Education: From Opportunity Growth to Integration into the Mainstream and Steady Development-The Enlightenment of American Online Higher Education Series Survey and Evaluation on the Development of Online Education in China", Open Education Research, 2006, pp. 10-17.

[9] J. Swller, "Cognitive Load During Problem Solving: Effects on Learning", Cognitive Science, 12(2), 1988, pp. 257-285.

[10] X. Zha, C. Huang, Y. Yan and J. Guo, "Progress of Foreign Cognitive Load Theory Application Research", Journal of the China Society for Scientific and Technical Information, 39(5), 2020, pp. 547-556. 
[11] L.Y. Li, and C.C. Tsai, "Accessing online learning material: Quantitative behavior patterns and their effects on motivation and learning performance", Computers \& Education, 114, 2017, pp. 286-297.

[12] M.R. Mônica, F.R. Jean, E. Isaac, and F. Pierre, "Effects of Online Reading on Popular Science Comprehension", Science Communication, 25(2), 2003, pp. 99-128.

[13] M.J. Eppler, and J. Mengis, "The concept of information overload: A review of literature from organization science, accounting, marketing", MIS Quarterly, 25(5), 2004, pp. 325-344.

[14] I.S. Chen, "Computer self-efficacy, learning performance, and the mediating role of learning engagement", Computers in Human Behavior, 72, 2017, pp. 362-370.

[15] H. Lee, L.P. Jan, and D.H. Bruce, "Optimizing cognitive load for learning from computer based science simulations", Joural of Educational Psychology, 98(4), 2006, pp. 902-913.

[16] R.L. Oliver, "A cognitive model of the antecedents and consequences of satisfaction decisions", Journal of Marketing Research, 17(4), 1980, pp. 460-469.

[17] T.C. Lin, S. Wu, J.S.C. Hsu, and Y.C. Chou, "The integration of value-based adoption and expectationconfirmation models: An example of IPTV continuance intention", Decision Support Systems, 54(1), 2012, , pp. 63-75.

[18] A. Bhattacherjee, "Understanding information systems continuance: an expectation-confirmation model", MIS Quarterly, 25(3), 2001, pp. 351-370.

[19] C.C. Wolverton, R. Hirschheim, W.C. Black, and, J. Burleson, "Outsourcing success in the eye of the beholder: examining the impact of expectation confirmation theory on IT outsourcing", Information \& Management, 57(6), 2020. pp. 32-41.

[20] Q. Wang, S. Yang, Z. Gao, “An eye - tracking study of website complexity from cognitive load perspective", Decision Support Systems, 62, 2014, pp. 1-10.

[21] H.M. Reis, S.S. Borges, and V.H.S. Durelli, "Towards reducing cognitive load and enhancing usability through a reduced graphical user interface for a dynamic geometry system: an experimental study", 2012 IEEE International Symposium on Multimedia, pp. 445-450.

[22] V. McKinney, K. Yoon, and F.M. Zahedi, "The measurement of Web-customer satisfaction: an expectation and disconfirmation approach", Information System Research, 13(3), 2002, pp. 296315.

[23] O. Bein, M. Trzewik, and A. Maril, "The role of prior knowledge in incremental associative learning: An empirical and computational approach", Journal of Memory and Language, 107, 2019, pp. 1-24.

[24] M.C. Davis, A.J. Zautra, and B.W. Smith, "Chronic pain, stress, and the dynamics of affective differentiation", Journal of Personality, 2004, pp. 1133-1160.
[25] F. Luthans, and B.J. Avolio, "The 'point' of positive organizational behavior", Journal of Organizational Behavior, 2009, pp. 291-307.

[26] Q. Wu, T. Ge, A. Emond, K. Foster, J.M. Gatt, K. Hadfield, and T.A. Wouldes, "Acculturation, resilience, and the mental health of migrant youth: a cross-country comparative study", Public Health, 2018, pp. 63-70.

[27] C.A. Kermott, J.R. ohnson, R. Sood, S.M. Jenkins, and A. Sood, "Is higher resilience predictive of lower stress and better mental health among corporate executives?", PLOSONE, 2019, pp. e0218092.

[28] J. Pinkerton, and P. Dolan, "Family support, social capital, resilience and adolescent coping", Child \& Family Social Work, 2007, pp. 219-228.

[29] D. Liu, "The Relationship between ChallengeHindrance Stressor, Role overload and Exhaustion: the Moderating Role of Resilience", Studies of Psychology and Behavior, 2015, pp. 115-124.

[30] Y. Tan, Q. Yuan, "Cognitive Load Theory and its Application and Prospect in Information System", Journal of Modern Information, 2019, pp. 160-169.

[31] L. Vygotsky, "Thought and language. Cambridge, MA: MIT Press", 1962.

[32] M.D. Dickey, "Teaching in 3D: Pedagogical affordances and constraints of 3D virtual worlds for synchronous distance learning", Distance Education, 2003, pp. 105-121.

[33] C.C. Ching, and A.W. Hursh, "Peer modeling and innovation adoption among teachers in online professional development", Computers \& Education, 2014, pp. 72-82.

[34] A, Grubišić, B, Žitko, S. Stankov, I. Šarić-Grgić, A. Gašpar, S. Tomaš, E. Brajković, T. Volarić, D. Vasić, and A, Dodaj,"A common model for tracking student learning and knowledge acquisition in different eLearning platforms, Journal of E-Learning and Knowledge Society, 16(3), 2020, pp. 10-23.

[35] A. Fotiadou, C. Angelaki, and I. Mavroidis, "Learner autonomy as a factor of the learning process in distance education", European Journal of Open, Distance and e-Learning, 20(1), 2017, pp. 95-110.

[36] M. Nückles, J. Roelle, I. Glogger-Frey, "The SelfRegulation-View in Writing-to-Learn: Using Journal Writing to Optimize Cognitive Load in Self-Regulated Learning", Educational Psychology Review, 2020, pp. 1089-1126.

[37] R. Arends, "Learning to teach, 9th Ed. New York: McGraw-Hill Companies”, 2012.

[38] J. Jung, D. Kim, and C. Na. "Effects of WOE presentation types used in pre-training on the cognitive load and comprehension of content in animation-based learning environments", Educational Technology \& Society, 19(4), 2016, pp. 75-86.

[39] J. Jung, Y. Shin, and J. Zumbach "The effects of pretraining types on cognitive load, collaborative knowledge construction and deep learning in a computer-supported collaborative learning environment", Interactive Learning Environments, 2019, pp. 1-13. 
[40] Y. Murat, and G. Abdurrahim, "COVID-19 severity, self-efficacy, knowledge, preventive behaviors, and mental health in Turkey, Death Studies", 2020, pp. 18.

[41] C. Liu, S. Wu, S. Wu, and S. Cai, "An AR-Based Case Study of Using Textual and Collaborative Scaffolding for Students with Different Self-Efficacy to Learn Lever Principles", Immersive Learning Research Network, 2020, pp. 9-15.

[42] U.M. Dholakia, "A motivational process model of product involvement and consumer risk perception", European Journal of Marketing, 35(11/12), 2001, pp. 1340-1362.

[43] V.A. Quintal, J.A. Lee, and G.N. Soutar, "Risk, uncertainty and the theory of planned behavior: A tourism example", Tourism Management, 31(6), 2010, pp. 797-805.

[44] C.K. Lee, H.J. Song, L.J. Bendle, M.J. Kim, and, H. Han, "The impact of non-pharmaceutical interventions for $2009 \mathrm{H} 1 \mathrm{~N} 1$ influenza on travel intentions: A model of goal-directed behavior", Tourism Managment, 33(1), 2012, pp. 89-99.

[45] M.F. Floyd, H. Gibson, G.L. Pennington, and, B. Thapa, "The effect of risk perceptions on intentions to travel in the aftermath of September 11, 2001", Journal of Travel \& Tourism Marketing, 2004, pp. 1938.

[46] B. Maser, and, K. Weiermair, "Travel decisionmaking: From the vantage point of perceived risk and information preferences", Journal of Travel \& Tourism Marketing, 7(4), 1998, pp. 107-121.

[47] M.J. Culnan, and P.K. Armstrong, "Information privacy concerns, procedural fairness, and impersonal trust: An empirical investigation", Organization Science, 10(1), 1999, pp. 104-115.

[48] N.K. Malhotra, S.S. Kim, and J. Agarwal, "Internet users' information privacy concerns (IUIPC): The construct, the scale, and a causal model", Information Systems Research, 15(4) ,2004, pp. 336-355.

[49] E. Ibili, and M. Billinghurst, "Assessing the Relationship between Cognitive Load and the Usability of a Mobile Augmented Reality Tutorial System: A Study of Gender Effects", International Journal of Assessment Tools in Education, 2019, pp. 1092-1096.

[50] J. Wirth, F. Stebner, and M. Trypke, "An Interactive Layers Model of Self-Regulated Learning and
Cognitive Load”, Educ Psychol, 32, 2020, pp. 11271149.

[51] C. Wang, T. Fang, and R. Miao. "Learning performance and cognitive load in mobile learning: Impact of interaction complexity", Journal of Computer Assisted Learning , 34(6), 2018, pp. 917927.

[52] Z. Wang, S.Y. Gong, S. Xu, and S.E. Hu,"Elaborated feedback and learning: Examining cognitive and motivational influences", Computers \& Education, 136, 2019, pp. 130-140.

[53] R.R. Baeza, and A.R. Kumar, "Perceived Usefulness of Multimodal Voice Assistant Technology", Proceedings of the Human Factors and Ergonomics Society Annual Meeting, 63(1), 2019, pp. 1560-1564.

[54] A. Al-Maskari, and M. Sanderson, "A Review of Factors Influencing User Satisfaction in Information Retrieval", Journal of the American Society for Information Science and Technology, 61(5), 2010, pp. 859-868.

[55] T. Dahlberg, J. Guo, J. Ondrus ,"A critical review of mobile payment research", Electronic Commerce Research and Applications, 14(5), 2015, pp. 265-284.

[56] E.L. Slade, M.D. Williams, and Y.K. DwivediMobile payment adoption: Classification and review of the extant literature, The Marketing Review, 13(2), 2013, pp. 167-190.

[57] F. Davis, "Perceieved usefulness, perceived ease of use , and user acceptance of information technology", MIS Quarterly, 13(3), 1989, pp. 319-341.

[58] A. Bhattacherjee, "Undestanding information systems continuance:an expectation-confirmation model", MIS Quarterly, 25(3), 2001, pp. 351-370.

[59] E.W. Anderson, C. Fornell, and D.R. Lehmann, "Customer Satisfaction, Market Share, and Profitability: Findings from Sweden", The Journal of Marketing, 1994, pp. 53-66.

[60] E.W. Anderson, and M.W. Sullivan, "The Antecedents and Consequences of Customer Satisfaction for Firms", Marketing Science, 1993, pp. 125-143.

[61] J.S. Adams, "Inequity in social exchange", Advances in Experimental Social Psychology, 2(4), 1965, pp. 267-299.

[62] G. Anil, Y. Anish, and M. Abhishe, "How preadoption expectancies shape post-adoption continuance intentions: An extended expectationconfirmation model", International Journal of Information Management, 52, 2020, pp. 102094. 